\title{
Axon Regeneration through Scaffold into Distal Spinal Cord after Transection
}

\author{
Bing Kun Chen, ${ }^{1}$ Andrew M. Knight, ${ }^{1}$ Godard C.W. de Ruiter, Robert J. Spinner, ${ }^{1}$ Michael J. Yaszemski, ${ }^{2}$ \\ Bradford L. Currier, ${ }^{2}$ and Anthony J. Windebank ${ }^{1}$
}

\begin{abstract}
We employed Fast Blue (FB) axonal tracing to determine the origin of regenerating axons after thoracic spinal cord transection injury in rats. Schwann cell (SC)-loaded, biodegradable, poly(lactic-co-glycolic acid) (PLGA) scaffolds were implanted after transection. Scaffolds loaded with solubilized basement membrane preparation (without SCs) were used for negative controls, and nontransected cords were positive controls. One or 2 months after injury and scaffold implantation, FB was injected $0-15 \mathrm{~mm}$ caudal or about $5 \mathrm{~mm}$ rostral to the scaffold. One week later, tissue was harvested and the scaffold and cord sectioned longitudinally $(30 \mu \mathrm{m})$ on a cryostat. Trans-scaffold labeling of neuron cell bodies was identified with confocal microscopy in all cell-transplanted groups. Large (30-50 $\mu \mathrm{m}$ diameter) neuron cell bodies were predominantly labeled in the ventral horn region. Most labeled neurons were seen 1-10 mm rostral to the scaffold, although some neurons were also labeled in the cervical cord. Axonal growth occurred bidirectionally after cord transection, and axons regenerated up to $14 \mathrm{~mm}$ beyond the PLGA scaffolds and into distal cord. The extent of FB labeling was negatively correlated with distance from the injection site to the scaffold. Electron microscopy showed myelinated axons in the transverse sections of the implanted scaffold 2 months after implantation. The pattern of myelination, with extracellular collagen and basal lamina, was characteristic of SC myelination. Our results show that FB labeling is an effective way to measure the origin of regenerating axons.
\end{abstract}

Key words: axonal tracing; biodegradable polymers; Fast Blue; Schwann cells; spinal cord injury

\section{Introduction}

$\mathbf{P}$ ATHologic (Quencer and Bunge, 1996) AND IMAgING (Bodley, 2002) studies of human spinal cord injury have shown tissue destruction with cysts and gliosis at the site of injury that interrupt connections and form a barrier to regeneration. In completely destructive injuries, function below the block can only be re-established by bypassing the area (Tadie et al., 2002) or by rebuilding functional tissue within the cyst or scar. Cell or growth factor injections alone are unlikely to direct regeneration through the extensively destroyed, disorganized tissue. We are using tissue engineering with biodegradable polymer scaffolds to bridge the gap. Replacement of a segment of cord would be suitable for many patients with massive damage to the cord and no residual functional tissue in the area (Quencer and Bunge, 1996; Bodley, 2002).

Adult central nervous system (CNS) neurons can regenerate when provided with a peripheral nervous system micro- environment (Richardson et al., 1980; Weinberg and Raine, 1980; David and Aguayo, 1981; Bray et al., 1987; Berry et al., 1988; Smith and Stevenson, 1988; Houle, 1991; Campbell et al., 1992; Guenard et al., 1993). Semi-permeable polymeric guidance channels have been used to deliver Schwann cells (SCs) to promote regeneration across lesions in peripheral nerve and spinal cord (Guenard et al., 1991, 1992; Vacanti and Langer, 1999; Iwata et al., 2006). Biodegradable polymers can simultaneously provide a tissue scaffold, a cell-delivery vehicle, and a reservoir for sustained drug delivery (Oudega et al., 2001; Friedman et al., 2002; Moore et al., 2006).

Different methods can be used to assess axon regrowth through these scaffolds. Retrograde tracing provides information about the cells of origin of axons that have reached a specific location (Bentivoglio et al., 1980). Conversely, anterograde tracing identifies the destination of axons originating from a defined neuron pool, such as cortical motor neurons (Xu et al., 1997; Bamber et al., 2001). Fast Blue (FB,

${ }^{1}$ Department of Neurology, ${ }^{2}$ Department of Orthopedic Surgery, Mayo Clinic, Rochester, Minnesota. 
4-benzoylamino-2,5-diethoxybenzenediazonium chloride hemi[zinc chloride]) has been used to study peripheral and central connections (Akintunde and Buxton, 1992; Kummer and Oberst, 1993; Russo and Conte, 1996; Casatti et al., 1999; Edoff et al., 2000; Bukowska et al., 2005; Kraus and Illing, 2005) and spinal cord injury (Xu et al., 1995, 1997; Chen et al., 1996; Russo and Conte, 1996; Asada et al., 1998; Bamber et al., 1999; Martin et al., 2000; Puigdellivol-Sanchez et al., 2002; Takami et al., 2002a, 2002b). Therefore, we used retrograde FB tracing to label cell bodies of neurons with axons projecting into or through a biodegradable polymer scaffold.

We aimed to quantitatively answer two questions: (1) Where do regenerating axons originate? and (2) How far can they grow beyond the scaffold into surviving cord tissue? We studied the effect of injection volume and the spread of dye from the injection site over time to optimize quantitative use of the technique. We subsequently injected dye at defined distances above and below a SC-loaded poly(lactic-co-glycolic acid) (PLGA) scaffold. This approach allows quantitative assessment of strategies designed to overcome the inhibitory milieu of the surviving but injured cord tissue.

\section{Materials and Methods}

\section{Animals}

All experiments involving animals were performed according to the guidelines of and approved by the Mayo Clinic Institutional Animal Care and Use Committee. Rats were housed according to National Institutes of Health and U.S. Department of Agriculture guidelines. They were kept on a 12-h light/dark cycle on a standard regimen, with food and water ad libitum. A total of 72 adult female Sprague-Dawley rats (Charles River Laboratories, Wilmington, MA; Harlan Laboratories, Indianapolis, IN), weighing 200 to $300 \mathrm{~g}$, were used. Female rats were used because of the ease of managing bladder expression and the decreased incidence of urinary tract infections compared with males. Bladders were expressed twice daily, and animals were given analgesics and antibiotics as necessary. All animals were cared for with 24-h availability of veterinarians experienced in managing spinal cord injury in rodents.

\section{Experimental groupings}

Eight rats were randomly assigned to each experimental group. Laminectomy was performed at the T9 or T10 vertebral level. To ensure correct and reproducible location, pins were placed above and below the laminectomy site after the spinal column was isolated (Fig. 1A). Complete spinal cord transection was performed at this level, and a 2-mm long, 7-channel, SC-loaded PLGA scaffold was implanted. One or 2 months later, FB was injected at $0 \mathrm{~mm}$ (the host-graft interface), $5 \mathrm{~mm}$ or $10 \mathrm{~mm}$ caudal to the scaffold (Fig. 1D). In another group, $\mathrm{FB}$ was injected $5 \mathrm{~mm}$ rostral to the point of transection and scaffold implantation (Fig. 1E), and tissue was harvested after 1 month. Negative control animals had transection at T9 followed by implantation of scaffolds containing solubilized basement membrane preparation (BMP) (Matrigel Matrix, BD Biosciences, San Jose, CA) but no SCs (Fig. 1C). Positive control animals had no spinal cord transection (Fig. 1B). In positive and negative controls, $0.6 \mu \mathrm{L}$ of FB was injected into the spinal cords at the T11 level ( $\sim 5 \mathrm{~mm}$ caudal to the position where scaffolds would be placed).

\section{Primary SC isolation and culture}

Primary neonatal SCs were obtained from sciatic nerves of P4 rats (Brockes et al., 1979; Porter et al., 1986). Pups were humanely killed by intraperitoneal injection of sodium pentobarbital (Sleepaway, Fort Dodge Animal Health, Fort Dodge, IA). Sciatic nerves from both legs were isolated and removed under aseptic conditions, stripped of connective tissue and epineurium, cut into $1-\mathrm{mm}^{3}$ pieces, and treated enzymatically for $45 \mathrm{~min}$ with $0.25 \%$ trypsin EDTA (Mediatech, Herndon, VA) and $0.03 \%$ collagenase (Sigma, St. Louis, $\mathrm{MO}$ ) in Hank's balanced salts solution (Gibco, Grand Island, NY). After digestion and mechanical dissociation, cells were pelleted at $800 \mathrm{rpm}$ for $5 \mathrm{~min}$, supernatant was removed, and cells were resuspended in $5 \mathrm{~mL}$ of DMEM/F12 medium containing $10 \%$ fetal bovine serum and $100 \mathrm{U} / \mathrm{mL}$ penicillin/ streptomycin (Gibco). Cells were plated onto laminin-coated 35-mm dishes (Falcon, Becton Dickinson Labware, Franklin Lakes, NJ) and incubated at $37^{\circ} \mathrm{C}$ in $5 \% \mathrm{CO}_{2}$ for $48 \mathrm{~h}$.

\section{Scaffold manufacturing and loading}

PLGA polymer scaffolds with 7 parallel channels $(660-\mu \mathrm{m}$ diameter) were fabricated by injection molding and solvent evaporation, as previously described (Moore et al., 2006). Scaffolds were cut into 2-mm lengths and washed in ethanol for $30 \mathrm{~min}$ with gentle shaking to sterilize the scaffolds and to remove any residual mold lubricant. Scaffolds were vacuum dried for $24 \mathrm{~h}$ to remove the ethanol, then sealed in sterilized glass vials and stored desiccated at $4^{\circ} \mathrm{C}$ until further use.

SCs were detached from dishes with trypsin-EDTA for 2 min and suspended at $5 \times 10^{5}$ cells $/ \mu \mathrm{L}$ in chilled BMP (Guenard et al., 1992; Xu et al., 1995). Each of the seven channels of the scaffold was loaded with cells using a gel-loading pipette tip under a microscope at $4^{\circ} \mathrm{C}$. The internal volume of each channel was $0.67 \mu \mathrm{L}$, for a final cell loading of $2.4 \times 10^{6}$ cells per scaffold. Loading efficiency was determined by immediately flushing out cells and counting in a hemocytometer for a sample of scaffolds. Cell-loaded scaffolds were incubated in DMEM/F12 medium with $10 \%$ fetal bovine serum for $24 \mathrm{~h}$ before implantation in vivo. SC phenotype of the cells was demonstrated by positive S100 immunostaining.

\section{Surgical procedures, spinal cord transection, and scaffold implantation}

Animals were anesthetized with intraperitoneal injection of $80 \mathrm{mg} / \mathrm{kg}$ ketamine (Fort Dodge Animal Health) and $5 \mathrm{mg} / \mathrm{kg}$ xylazine (Lloyd Laboratories, Shenandoah, IA). The back was shaved and aseptically prepared with a povidone-iodine scrub swabstick (Professional Disposables, Orangeburg, NY). Puralube Vet Ointment (Pharmaderm, Melville, NY) was applied to protect the eyes from dehydration during the relatively long procedure. Animals were kept on a heating pad to maintain body temperature at $37^{\circ} \mathrm{C} \pm 0.5^{\circ} \mathrm{C}$ during surgery. A Zeiss F-170 microsurgical microscope (Oberkochen, Germany) was used during the entire surgical procedure. After skin incision and laminectomy at the T9-T10 vertebral levels, the spinal cord was completely transected with a sharp blade. After transection, the spinal cord retracted from the lesion site and left a 2-mm gap at the T9 spinal cord level. All spinal roots visible in the transection gap were removed. A 2-mm-long scaffold loaded with SCs was implanted in the gap and aligned with 

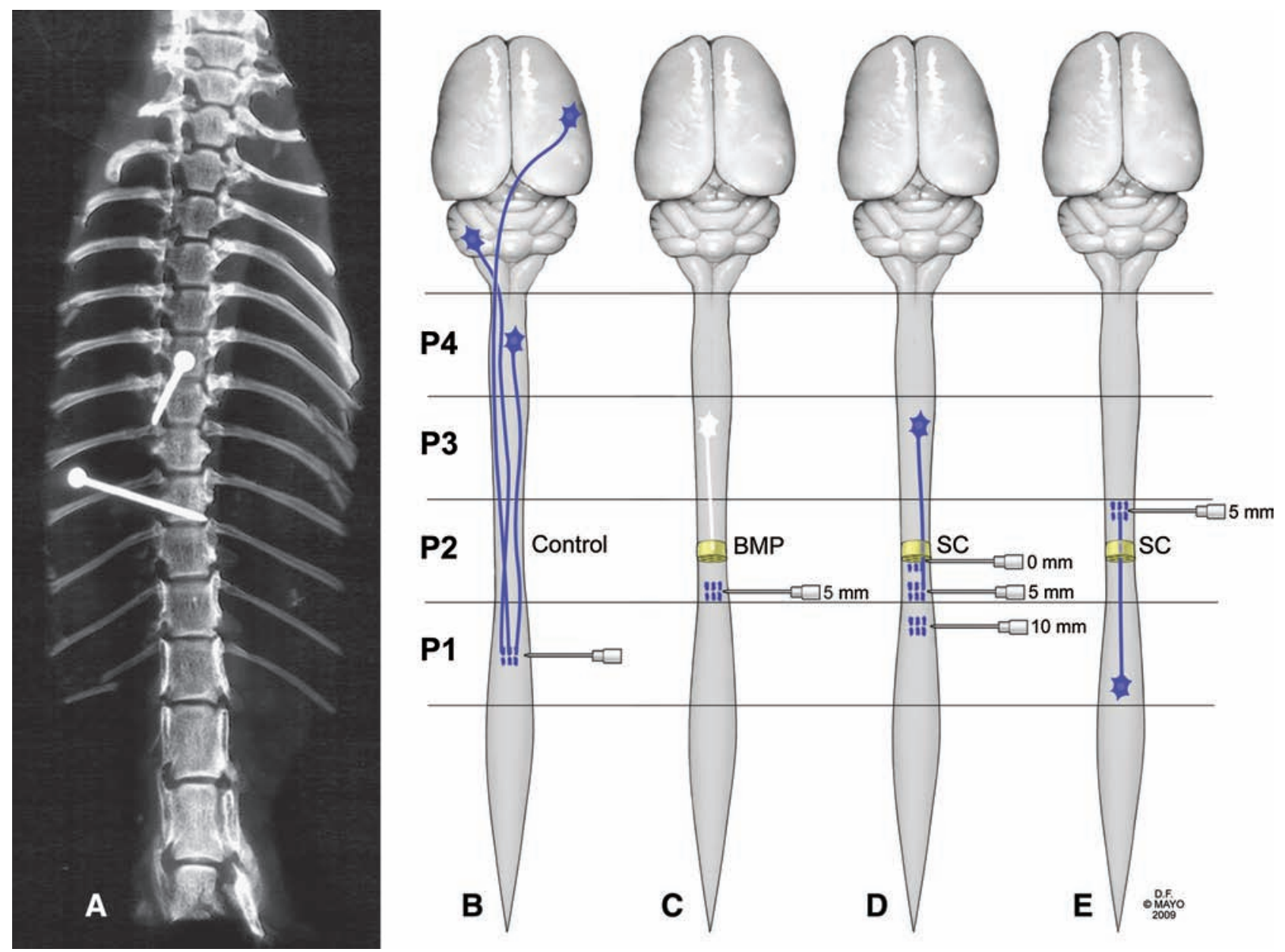

FIG. 1. Diagram of experimental designs. (A) Fixation pins were placed above and below the level of the T9-10 laminectomy to confirm reproducible location of the transection. (B-E) Fast Blue (FB) fluorescent dye $(0.6 \mu \mathrm{L})$ was injected via Hamilton syringe into the thoracic spinal cords of adult female rats at different levels. One week later, tissue was harvested and frozen and the cord sectioned longitudinally $(30 \mu \mathrm{m})$ on a cryostat. (B) Positive control: FB injection at the T11 level without transection and implantation of scaffold $(n=8)$. (C) Negative control: FB injection at the T11 level, with transection and implantation of scaffold loaded with solubilized basement membrane preparation $(B M P)(n=8)$. (D) Experimental groups with caudal FB injection at different levels of the spinal cord $(0,5$, or $10 \mathrm{~mm}$ caudal to the transection and scaffold loaded with Schwann cells [SCs]) 1 or 2 months after transection/implantation (total, $n=48$ ). (E) Experimental group with FB injection at the T7 level of the spinal cord $(5 \mathrm{~mm}$ rostral to the transection and scaffold loaded with SCs) 1 month after transection/implantation $(\mathrm{n}=8)$. P1-P4, 15- mm segments of spinal cord (caudal to rostral). (Used with permission from the Mayo Foundation for Medical Education and Research). (Color image is available online at www.liebertpub.com/jon)

the rostral and caudal spinal cord stumps. Muscles and skin were sutured separately. Animals in the negative control group were treated the same, except that the implanted scaffolds were loaded with BMP but no cells. Positive control animals had no cord transection and no sham surgery.

\section{Dye diffusion studies}

We injected FB into the spinal cord at the T11 level in a group of unoperated rats to determine the rate and distance of dye diffusion from the site of injection. Different volumes $(0.1-1.0 \mu \mathrm{L})$ of FB were injected into normal cord and tissue harvested after various intervals ( $0-7$ days). Two animals were used for each volume and time condition (20 rats total).

The effects of injection volume and time of harvesting after injection were evaluated in parallel. For studies regarding time after injection, $0.6 \mu \mathrm{L}$ FB was injected; tissue was harvested immediately ( 0 hour), after $2 \mathrm{~h}$, or after 1,3 , or 7 days. For the 0-h time point, care was taken to freeze the cord in situ immediately after injection and to transfer the 1-cm segment around the injection site en bloc to the cryostat chamber. The whole cord was longitudinally cryosectioned $(30 \mu \mathrm{m})$, and the area of dye was measured in every fifth section using scanning confocal microscopy (Fig. 2). The total volume containing dye was calculated by assuming that the dye was contained in an ellipsoid with volume $4 / 3 \pi r_{1} r_{2} h$, where $r_{1}$ is the maximum measured horizontal radius, $\mathrm{r}_{2}$ the maximum measured coronal radius, and $h$ the maximum rostrocaudal height of the dye-labeled area. For the injection volume studies, $0.1-1.0 \mu \mathrm{L}$ of dye was injected, and tissue was harvested after 7 days. Volume of diffusion was measured by the same technique. 

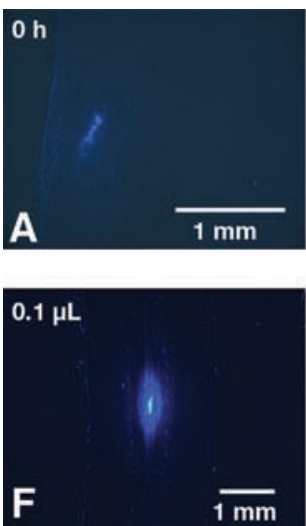
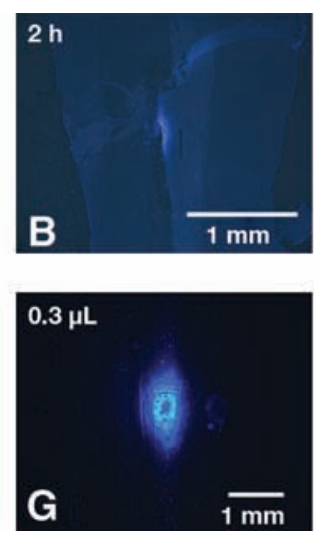
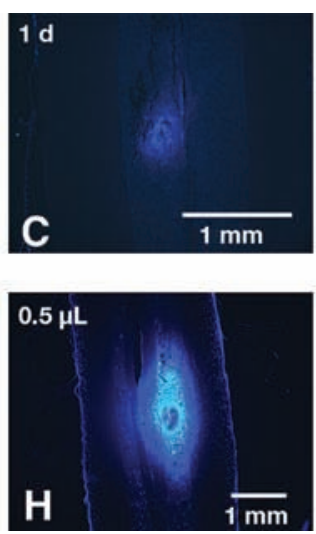
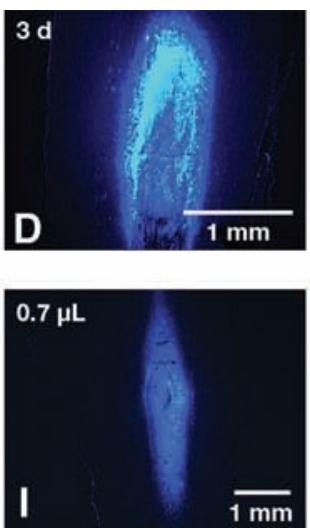
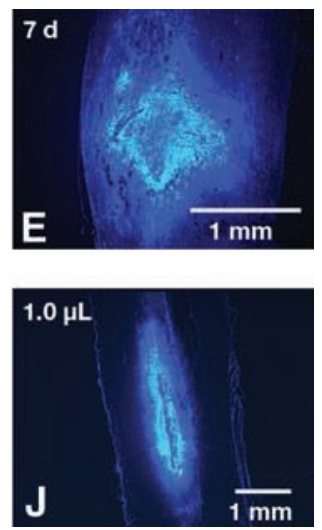

FIG. 2. Halo of FB injection. (A-E) FB $(0.6 \mu \mathrm{L})$ was injected and tissue was harvested immediately $(0 \mathrm{~h}$, frozen in situ) or at $2 \mathrm{~h}$ or 1,3 , or 7 days. The whole cord was longitudinally cryosectioned $(30 \mu \mathrm{m})$ and the area of dye spread measured in every fifth section using scanning confocal microscopy with the motorized stage. (F-J) Using similar techniques, $0.1-1.0 \mu \mathrm{L}$ of dye was injected and tissue harvested after 7 days. (Color image is available online at www.liebertpub.com/jon)

\section{Retrograde tracing with $F B$}

One or 2 months after scaffold implantation, the injury site was re-exposed, and $0.6 \mu \mathrm{L}$ of $5 \%$ aqueous FB (Polysciences Europe $\mathrm{GmBH}$, Eppelheim, Germany), was stereotactically injected into the thoracic spinal cord $(0 \mathrm{~mm}, 5 \mathrm{~mm}$, or $10 \mathrm{~mm}$ caudal, or $5 \mathrm{~mm}$ rostral, to the transection/scaffold) using a needle (gauge, 26s $/ 2^{\prime \prime} / 2$ ) attached to a $10-\mu \mathrm{L}$ Hamilton syringe (Reno, NV). All injections were performed over $1 \mathrm{~min}$, and the injection needle was kept in place for an additional minute to minimize leakage on withdrawal. The scaffold was not visualized during this procedure.

\section{Postoperative care of animals}

All rats were injected with $5.0 \mathrm{~mL}$ lactated Ringer's solution subcutaneously after surgery and allowed to recuperate. Changes in body weight were monitored daily. If an animal lost more than $5 \%$ of its body weight during the course of one day, a subcutaneous injection of saline solution (Baxter Healthcare, Deerfield, IL) was given. The rats were kept in low-sided, warmed cages to enable them easy access to food and water, and bedding was changed frequently to prevent decubitus ulcers. Buprenex $(0.05 \mathrm{mg} / \mathrm{kg}$; Reckitt Benckiser Pharmaceuticals, Richmond, VA) was administered intramuscularly twice daily for 3 to 5 days to minimize pain after surgery. Acetaminophen was given if needed. Baytril $(65 \mathrm{mg} / \mathrm{kg}$; Bayer, Shawnee, KS) was given intramuscularly for 1 week and as needed thereafter to prevent infection. Bladders were emptied manually twice daily for the whole duration of the experiment.

\section{Tissue preparation and sectioning}

For the dye diffusion studies, animals were humanely killed immediately $(0 \mathrm{~h})$ or at $2 \mathrm{~h}$, or 1,3 , or 7 days after injection. For the tracing experiments, animals were humanely killed and transcardially perfused with fixative (4\% paraformaldehyde, $10 \%$ sucrose) 1 week after FB injection. The brain, spinal cord, and implants were removed en bloc and postfixed in the same fixative overnight at $4^{\circ} \mathrm{C}$. Brain and spinal cord were isolated, fixed again in the same fixative overnight at $4^{\circ} \mathrm{C}$, and then transferred to phosphate-buffered $15 \%$ sucrose solution for
$24 \mathrm{~h}$ at $4{ }^{\circ} \mathrm{C}$ before they were processed for cryostat embedding with tissue freezing medium (Triangle Biomedical Sciences, Durham, NC). The position of the scaffold was identified and used as the midpoint of a $15-\mathrm{mm}$ segment of the cord. The segment (designated P2) contained $6.5 \mathrm{~mm}$ of cord rostral to the scaffold, the $2-\mathrm{mm}$ scaffold, and $6.5 \mathrm{~mm}$ of caudal cord. The remainder of the cord was cut into $15-\mathrm{mm}$ contiguous segments that corresponded to different levels of the spinal cord: T10-L3 (designated P1), T6-T10 (P2), T1-T5 (P3), and craniocervical junction to $\mathrm{C} 8$ (P4) (Fig. 1). P1 contained the FB injection site, and the rostral end of $\mathrm{P} 4$ was at the junction of the brainstem and cervical cord. The brain was divided at the rostral mid brain level (approximately at the level of the red nucleus). The spinal cord segments were cut longitudinally, and the entire brain was cut horizontally into $30-\mu \mathrm{m}$ sections (Reichert HistoSTAT, Cryostat Microtome, Leica Microsystems, Bannockburn, IL). Sections were carefully numbered and sequentially collected as five sections per slide.

\section{Visualization and counting of FB-labeled neurons}

The Tissue Freezing Medium-embedded spinal cord and brain sections were viewed with a laser scanning confocal microscope (LSM510, Zeiss). FB-labeled images were captured using a $C$-Apochromat $\times 10$ or $\times 20$ objective lens $(0.45 \mathrm{NA})$. The pinhole was set to give a $1-\mu \mathrm{m}$ optical slice. The blue fluorescence of FB-labeled neurons and axons was visualized with excitation from the $358 \mathrm{~nm}$ line of an argon/krypton laser. Emission was collected through a 467-nm long-pass filter. In animals of each group (0-, 5-, and $10-\mathrm{mm}$ caudal injection; 5 -mm rostral injection; positive and negative controls), FBlabeled neurons were counted in different segments of the spinal cord and areas of the brain. All identified neurons with a visible nucleus and whole cell body were counted, and the mean of the values from the cord segment or brain area was used for analysis. Cells were only counted if they were outside the halo of dye that diffused around the injection site.

\section{Measurement of FB-labeled axon tracing distances}

Distance from the injection site to individual, labeled neuron cell bodies was measured by using the motorized stage of 
the laser scanning confocal microscope. At the time of tissue harvesting and analysis, it was possible to accurately measure distances. The injection site was marked with a line perpendicular to the long axis of the cord and was used as the starting point with the stage set to 0 . For cell bodies in P2, P3, and P4, the distance was measured from the center of the cell body to the caudal edge of the section, which was assumed to be immediately adjacent to the rostral end of the previous segment. Distances were determined by the distance the stage traveled, as displayed by the microscope software. For every labeled neuron, the distance from cell body to the line of origin (parallel to the long axis of the cord) was calculated. This generated a series of values from each section in a spinal cord. Sections were randomized so that the observers making the measurements were unaware of the experimental group or time of tracing ( 1 or 2 months). In addition, the distance from the actual FB injection site to the scaffold was measured.

\section{Light and electron microscopy}

An additional group of four animals survived for 2 months after cord transection and implantation of scaffold seeded with SCs. The animals were humanely killed and then perfused with $4 \%$ paraformaldehyde in phosphate buffer. The spinal cord and implants were removed en bloc and postfixed in the same fixative overnight. The isolated spinal cords were fixed in Trumps solution (4\% formaldehyde, 1\% glutaraldehyde in phosphate buffer) for $48 \mathrm{~h}$ at $4{ }^{\circ} \mathrm{C}$. Specimens were postfixed in osmium tetroxide, dehydrated, and embedded in epoxy resin for transmission electron microscopy. Sections through the scaffold were cut at $1.5 \mu \mathrm{m}$ for light microscopy and $0.1 \mu \mathrm{m}(100 \mathrm{~nm})$ for transmission electron microscopy.

\section{Statistical methods}

Tracing distances and number of labeled neurons were described by mean and SD. Difference in number of labeled neurons between groups was analyzed with one-way analysis of variance (ANOVA). Multiple linear regression analyses were used to determine if the number of FB-labeled neurons correlated with the actual distance from the injection site to the scaffold. $P$ values less than 0.05 were considered significant.

\section{Results}

\section{FB diffusion after injection}

Table 1 and Figure 2 show the effects of volume of dye injection and time after injection on dye spread. Immediately after injection of $0.6 \mu \mathrm{L}$ of FB, cells were not labeled, but a small volume of visible dye (mean measured volume, $0.1 \mu \mathrm{L}$ ) and dye crystals were present at the injection site (Fig. 2A). After $2 \mathrm{~h}$, cell labeling was visible (mean, $0.26 \mu \mathrm{L}$ at the injection site). This volume increased at days 1,3 , and 7 (Table 1). Linear regression analysis of the volume course showed a direct (linear) relationship between volume of dye injected and measured volume of label after 7 days (mean [SD] slope, $7.6[1.1] ; r^{2}=0.94 ; p=0.006$ ) (Table 1).

For all subsequent experiments, $0.6 \mu \mathrm{L}$ of FB was injected, and tissue was harvested after 7 days. Addition of larger volumes appeared to increase the rostrocaudal spread of dye. The mean rostrocaudal radius of the "halo" around the injection site was $1.1 \mathrm{~mm}$. No abnormal locomotor function was observed in animals after FB injection without cord transection.
Table 1. Dye Diffusion Studies

\begin{tabular}{lcc}
\hline Experiment & Measured volume $(\mu L)^{\mathrm{a}}$ & \\
\hline Time course $^{\mathrm{b}}$ & & \\
$0 \mathrm{~h}$ & 0.09 & 0.12 \\
$2 \mathrm{~h}$ & 0.24 & 0.28 \\
$1 \mathrm{~d}$ & 0.93 & 0.98 \\
$3 \mathrm{~d}$ & 2.29 & 2.48 \\
$7 \mathrm{~d}$ & 2.32 & 2.49 \\
Volume injected $(\mu \mathrm{L})^{\mathrm{c}}$ & & \\
0.1 & 0.34 & 0.39 \\
0.3 & 0.53 & 0.58 \\
0.5 & 2.11 & 2.18 \\
0.7 & 3.61 & 3.67 \\
1 & 6.98 & 7.07 \\
\hline
\end{tabular}

${ }^{\mathrm{a}}$ Values are the measured volumes for 2 rats per injection.

${ }^{\mathrm{b}}$ Fast Blue $(0.6 \mu \mathrm{L})$ was injected into the spinal cord and tissue harvested at the time indicated.

${ }^{\mathrm{C}}$ Increasing volumes of dye were injected as shown and the spinal cord tissue harvested after 7 days.

In all animals, examination of longitudinal sections of spinal cord at the injection site showed a small defect caused by the needle, with a surrounding ellipsoid of labeled cells (Fig. 3A). Multiple labeled axons were visible in the rostral cord extending from the injection site in cord segments adjacent to the injection site (Fig. 3B).

\section{Number of neurons labeled in spinal cord and brain nuclei}

Analysis of neuron labeling was performed in control and experimental animals at the specified time points. Not all animals survived until this analysis, however, and others were excluded because of unsuccessful labeling of cells. Therefore, analysis of all eight animals in each group was not possible.

Control groups. In positive controls (without transection), FB-labeled neuron cell bodies were observed in multiple areas of the spinal cord and brain (Fig. 4). In the brain, we identified clusters of labeled neurons in four limited areas designated pons, midbrain, deep subcortical nuclei, and frontal cortex. Because these were transverse, $30-\mu \mathrm{m}$ frozen sections, precise identification of specific nuclei was not possible. We used the three-dimensional rat brain atlas from the Laboratory of Neuro Imaging, University of California at Los Angeles, to identify locations of the labeled cell clusters (LONI Image Viewer, 2008). Neurons were heavily labeled in segments P1 and P2, which are close to the injection site. In these areas (Fig. $4 \mathrm{~A}$ and $\mathrm{B})$, cell processes were labeled with punctate labeling around cells, representing boutons terminaux and dendritic expansions.

The number of labeled cell bodies in P1 (injection site) was not significantly different between positive controls $(6,045$ $[1,171]$ ) and negative controls (transection with implantation of scaffold without SCs) $(6,147$ [1,152], Table 2$)$. In the positive control animals, the number of labeled neurons decreased with distance from injection site (Table 2). In these nonoperated animals, labeled neuron cell bodies were identified in the pons, midbrain, deep subcortical nuclei, and frontal cortex (Fig. 4E-H). No labeled neurons and axons were 

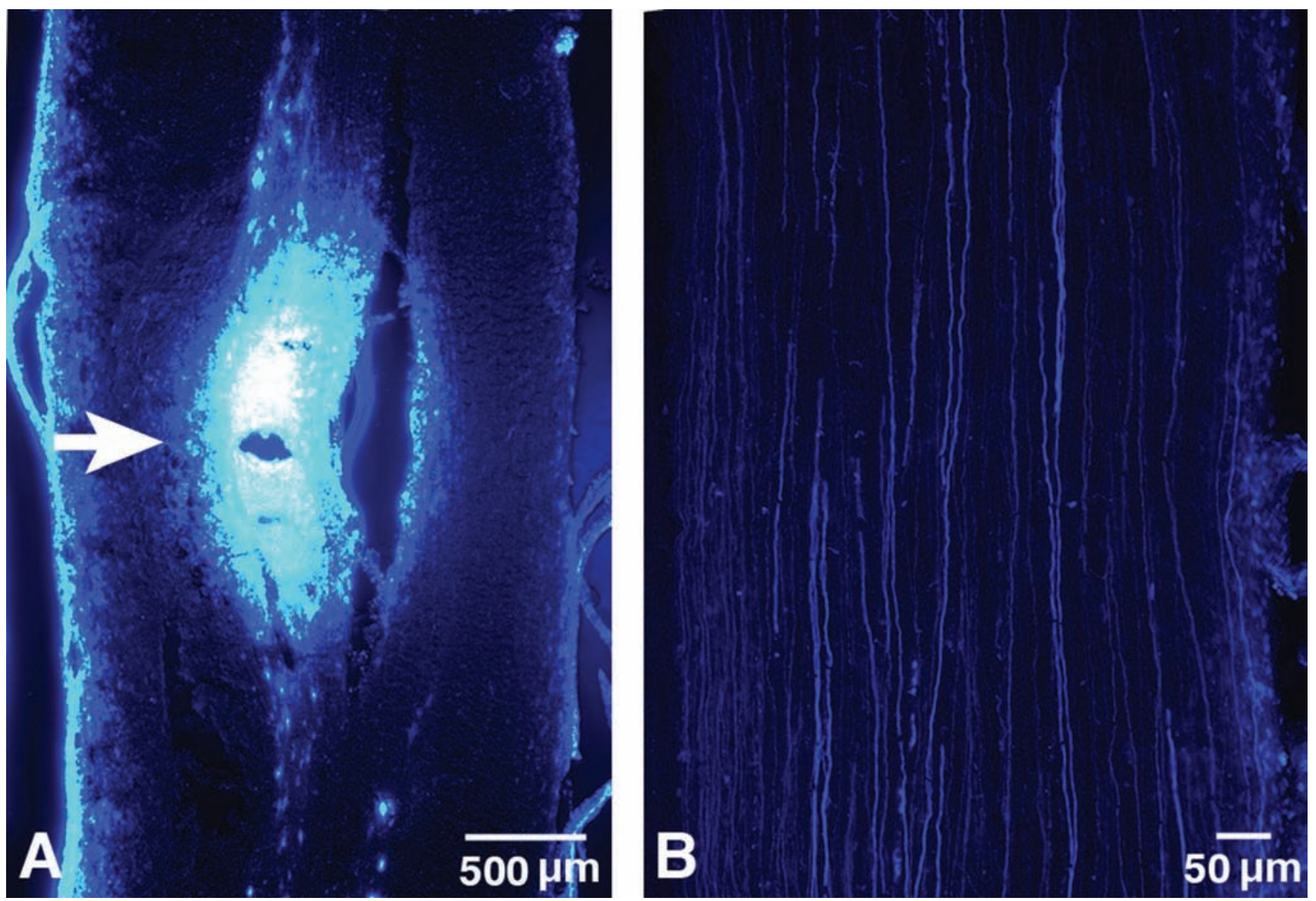

FIG. 3. Confocal microscopic images of FB injection areas. (A) Representative longitudinal section of rat spinal cord shows the injection site (white arrow) and labeled axons adjacent to the injection site. The FB diffusion area was $\sim 2.2 \times 1.1 \mathrm{~mm}$. (B) FB labeling of axons (fluorescent filaments) extending from the injection site. (Color image is available online at www.liebertpub.com/jon)

observed in the spinal cord (P2, P3, and P4 segments) or brain of negative control animals, confirming that BMP-loaded scaffolds did not facilitate axons growing through the scaffold into distal tissue (Table 2).

Transection/implantation groups. All rats with spinal cord transection had hind limb paralysis. At the gross tissue level, no obvious scarring or fibrosis was seen at the host-graft interface, and implanted scaffolds were well integrated into the spinal cords. Evaluation of the FB injection site showed that the FB had been correctly injected into the lower thoracic spinal cord in all cases. Similar numbers of labeled cells were observed at the injection site (P1) in all the different scaffold experimental groups (Tables 3-5), which indicates approximately equal "loading" of dye at the injection site. FB-labeled axons, seen by confocal microscopy as fluorescent blue, single scattered filaments or groups of small fascicles, were observed throughout the scaffold (Fig. 5A). Most FB-labeled neurons rostral to the scaffold were large ( $\sim 10-20 \mu \mathrm{m}$ in diameter) and located in the middle of the cord (grey matter), predominantly in the ventral horn region (Fig. 5B-D).

One month after transection/implantation, the number of labeled neurons rostral to the scaffold decreased with distance above the scaffold (Table 3). Numbers also decreased with increasing distance of the injection site from the scaffold
(Table 3). The number of labeled neurons in the P2 segment was significantly higher in the $0-\mathrm{mm}$ injection group (579 [273]) than in both 5-mm (198 [99]) and 10-mm (71 [17]) groups ( $p<0.05$ and $p<0.01$, respectively). Similarly, in the P3 segment, the number of labeled neurons was significantly higher in the 0 -mm group (148 [85]) than in both 5-mm (26 [10]) and 10-mm (7.7 [4.0]) injection groups ( $p<0.05$ in both) (Table 3). In both P2 and P3 segments, the number of labeled cells in the $5-\mathrm{mm}$ injection group was higher than in the $10-\mathrm{mm}$ group, but the difference was not statistically significant $(p>0.05)$. A small number of labeled neurons was seen in the P4 segment in the $0-\mathrm{mm}$ injection group (9 [7]), compared with none in the $5-\mathrm{mm}$ and $10-\mathrm{mm}$ injection groups. FBlabeled neurons were not found in supraspinal areas.

A similar distribution of labeled neurons was seen 2 months after transection/implantation (Table 4). Fewer labeled neurons rostral to the scaffold were seen in all segments at 2 months than at 1 month. The difference was only significant for the P2 segment with injection at $0 \mathrm{~mm}$ (ANOVA, $p<0.01$ ) (Tables 3 and 4). Two months after transection/ implantation, the number of labeled neurons in the P2 segment was similar in the 0-mm (157 [61]) and 5-mm groups (127 [27]; $p>0.05$ ), but both were significantly higher than in the 10-mm injection group (34 [11]; $p<0.05$ ). However, the number of regenerated neurons in the P3 segment was sig- 


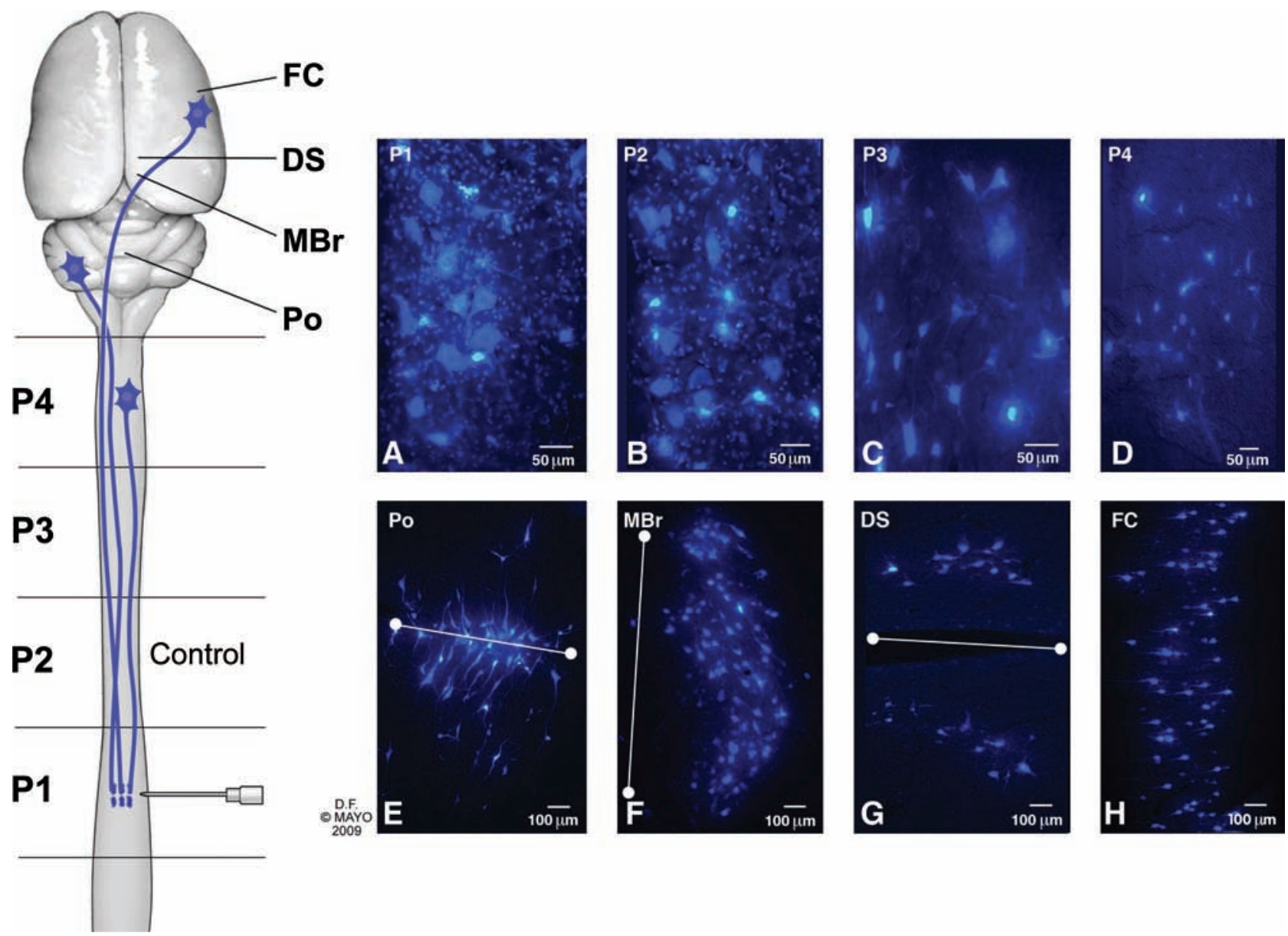

FIG. 4. Confocal microscopic images from sections of normal spinal cord and brain (positive controls) showing FB-labeled neurons. (A-D) Longitudinal sections showing labeled neuron cell bodies in different segments of the spinal cord (P1-P4). Neurons were typically 10 to $20 \mu \mathrm{m}$ in diameter and located in the anterior and central grey matter regions of the cord. (E-H) Horizontal sections of rat brain showing FB-labeled neuron cell bodies in different areas of the brain. (E) The section designated pons (Po) was located in the brainstem at the level of the middle cerebellar peduncle. Cells were clustered along the midline (white line), predominantly in the basis pontis. (F) Cells in the midbrain (MBr) were arranged in an arc lateral to the caudal end of the fourth ventricle (midline delineated with white line). (G) Labeled neurons in the deep subcortical (DS) region were parallel to the slit-like third ventricle (midline delineated with white line). $(\mathrm{H})$ Neurons in the region of the frontal cortex (FC) were pyramidal in shape with axons projecting toward the midline. (Used with permission from the Mayo Foundation for Medical Education and Research.) (Color image is available online at www.liebertpub.com/jon)

nificantly higher for the 0-mm injection than for both the 5-mm and 10-mm injection groups (Table $4, p<0.01$ and $p<0.001$, respectively). The number of regenerated neurons in the P4 segment was also significantly higher in the $0-\mathrm{mm}$ injection group (3.3 [1.5]) than in both $5-\mathrm{mm}$ and $10-\mathrm{mm}$ injection groups ( 0 neurons in both groups; $p<0.01$ ) (Table 4 ).

When FB was injected $5 \mathrm{~mm}$ rostral to the transection/ implantation site, labeled neurons were observed caudal to the scaffold in the P2 (663 [100]) and P1 (15.3 [2.5]) segments (Table 5), demonstrating that ascending axonal regeneration had occurred through the scaffold, in addition to the observed descending regeneration. The numbers of labeled neurons above the scaffold after caudal injection and below the scaffold after rostral injection were similar after 1 month (Tables 3 and 5). The numbers of FB-labeled neurons in P3 and P4 or in brain were not significantly different between nontransected animals and the rostral injection group (ANOVA, $p=0.93$ ), demonstrating consistency of the injection technique.

\section{Measurement of tracing distances}

For each animal, the distances between the actual injection site and labeled neuron cell bodies were measured. In the 0-mm injection groups, the most-rostral labeled neurons were observed in P4, with distances from cell body to injection site of 34.4 (1.5) $\mathrm{mm}$ after 1 month and 33.4 (1.7) $\mathrm{mm}$ after 2 months (Tables 3 and 4). In the 5-mm caudal injection groups, the most-rostral labeled neurons were in P3, with mean distances of 27.1 (1.8) mm after 1 month and 29.0 (1.8) mm after 2 months (Tables 3 and 4). In the $10-\mathrm{mm}$ caudal injection groups, the most-rostral neurons were in P3 after 1 month $(27.0[1.4] \mathrm{mm})$ and $\mathrm{P} 2$ after 2 months (17.4 [2.5] mm) (Tables 3 and 4$)$.

When dye was injected $5 \mathrm{~mm}$ rostral to the scaffold, most labeled neurons were seen in the P2 segment, with a mean distance of 10.1 (1.0) $\mathrm{mm}$ from injection site to cell body. In P1 (sacral cord), the mean distance was 11.9 (2.1) mm (Table 5). 
Table 2. FB-labeled Neurons in Different Segments of Spinal Cord and Brain in Control Rats

\begin{tabular}{ccccc}
\hline & & & \multicolumn{2}{c}{ Distance $(m m)^{\mathrm{a}}$} \\
\cline { 3 - 5 } Group & Segment & $\begin{array}{c}\text { Mean }(S D) \\
\text { cells }\end{array}$ & $\begin{array}{c}\text { Mean } \\
(S D)\end{array}$ & Longest \\
\hline Positive & P1 & $6,045(1,171)$ & - & - \\
controls & P2 & $22,522(2,282)$ & $11.7(1.3)$ & 13.6 \\
& P3 & $13,390(1,432)$ & $27.1(1.8)$ & 29.7 \\
& P4 & $10,506(2,157)$ & $42.1(1.9)$ & 44.8 \\
Brain & $7,256(1,652)$ & - & - \\
Negative & P1 & $6,147(1,152)$ & - & - \\
controls & P2 & $0(0)$ & NA & NA \\
& P3 & $0(0)$ & NA & NA \\
& P4 & $0(0)$ & NA & NA \\
& Brain & $0(0)$ & NA & NA \\
\hline
\end{tabular}

${ }^{a}$ From cell body to center of injection site.

FB, Fast Blue; NA, not applicable.

Linear regression analysis of the data from the 1- and 2-month injection groups showed a significant negative correlation between the number of labeled neurons and the distance between the actual injection site and the scaffold ("actual injection distance") (Fig. 6A and B). This was true for all labeled neurons in the 1-month injection group in segments P2 $\left(r^{2}=0.80, p=0.001\right)$, P3 $\left(r^{2}=0.63, p=0.01\right)$, and P4 $\left(r^{2}=0.74, p=0.003\right)$ (Fig. 6A), and in the 2-month injection group, in segments P2 $\left(r^{2}=0.81, p=0.001\right)$, P3 $\left(r^{2}=0.91\right.$, $p<0.001)$, and P4 $\left(r^{2}=0.68, p=0.006\right)$ (Fig. 6B).

\section{Microscopy}

Two animals each with SC-seeded scaffolds were humanely killed 1 and 2 months after implantation. The profiles of the seven tissue-filled channels were observed in the scaffold with light microscopy (Fig. 7A). Myelinated axons with typical SC morphology, including extracellular deposition of collagen and basal lamina, were identified with electron microscopy (Fig. 7B and C).

Table 3. FB-Labeled Neurons in Transected SPINAL Cord After 1 Month

\begin{tabular}{lcccc}
\hline & & & \multicolumn{2}{c}{ Distance $(m m)^{\mathrm{a}}$} \\
\cline { 3 - 5 } Group & Segment & Mean (SD) cells & Mean (SD) & Longest \\
\hline 0-mm & P1 & $6,255(510)$ & - & - \\
injection & P2 & $579(273)$ & $8.9(0.6)$ & 9.6 \\
& P3 & $148(85)$ & $20.7(1.0)$ & 22.3 \\
5-mm & P4 & $9(7)$ & $34.4(1.5)$ & 36.5 \\
injection & P1 & $6,968(902)$ & - & - \\
& P2 & $198(99)$ & $12.5(1.0)$ & 13.7 \\
10-mm & P3 & $26(10)$ & $27.1(1.8)$ & 29.5 \\
injection & P1 & $0,950(635)$ & NA & NA \\
& P2 & $71(17)$ & $15.0(1.9)$ & 17.5 \\
& P3 & $7.7(4.0)$ & $27.0(1.4)$ & 28.6 \\
& P4 & $0(0)$ & NA & NA \\
\hline
\end{tabular}

${ }^{\mathrm{a}}$ From cell body to center of injection site.

FB, Fast Blue; NA, not applicable.
Table 4. FB-labeled Neurons in Transected SPINAL Cord After 2 Months

\begin{tabular}{|c|c|c|c|c|}
\hline \multirow[b]{2}{*}{ Group } & \multirow[b]{2}{*}{ Segment } & \multirow[b]{2}{*}{ Mean (SD) cells } & \multicolumn{2}{|c|}{ Distance $(\mathrm{mm})^{\mathrm{a}}$} \\
\hline & & & Mean (SD) & Longest \\
\hline \multirow{4}{*}{$\begin{array}{l}0-\mathrm{mm} \\
\text { injection }\end{array}$} & P1 & $6,947(356)$ & - & - \\
\hline & P2 & $157(61)$ & $7.68(1.1)$ & 9.3 \\
\hline & P3 & $72(22)$ & $19.1(1.9)$ & 21.6 \\
\hline & P4 & $3.3(1.5)$ & $33.4(1.7)$ & 35.3 \\
\hline \multirow{4}{*}{$\underset{\text { injection }}{5-\mathrm{mm}}$} & P1 & 5,707 (642) & - & - \\
\hline & P2 & $127(27)$ & $12.6(1.4)$ & 14.6 \\
\hline & P3 & $22(3)$ & $29.0(1.8)$ & 31.5 \\
\hline & P4 & $0(0)$ & NA & NA \\
\hline \multirow{4}{*}{$\begin{array}{l}\text { 10-mm } \\
\text { injection }\end{array}$} & P1 & 7,972 (403) & - & - \\
\hline & P2 & $34(11)$ & $17.4(2.5)$ & 20.7 \\
\hline & P3 & $0(0)$ & NA & NA \\
\hline & P4 & $0(0)$ & NA & NA \\
\hline
\end{tabular}

${ }^{a}$ From cell body to center of injection site.

FB, Fast Blue; NA, not applicable.

\section{Discussion}

We showed that tissue engineering with a biodegradable polymer scaffold loaded with SCs supports regeneration that can be reliably quantified. This scaffold provides a platform in which the contributions of extracellular architecture, donor cells, and microenvironment may be separately manipulated to assess their contributions to successful regeneration. The donor cells re-created a peripheral nerve microenvironment within the channels of scaffold, with typical extracellular basal lamina and collagen fibrils. In addition, we showed that retrograde labeling with FB is a reproducible and quantitative method for measuring regeneration after spinal cord injury.

FB is a diamidino dye that is taken up by cells, is transported over long distances, and remains in the cytoplasm. Axons, dendrites, and neuron cell bodies are rendered visible when the dye is sufficiently concentrated. After the dye is injected, it diffuses away from the injection site through the extracellular space. Varying volumes of dye $(0.1-1.0 \mu \mathrm{L})$ have been injected in spinal cord injury studies (Xu et al., 1995, 1997; Russo and Conte, 1996; Asada et al., 1998; PuigdellivolSanchez et al., 2002; Takami et al., 2002a, 2002b). To our knowledge, this is the first study to examine the range of

Table 5. FB-labeled Neurons in Transected SPINAL Cord AND BRAIN After 1 Month WITH ROSTRAL FB INJECTION

\begin{tabular}{ccccc}
\hline & & & \multicolumn{2}{c}{ Distance $(m m)^{\mathrm{a}}$} \\
\cline { 3 - 5 } Group & Segment & $\begin{array}{c}\text { Mean }(S D) \\
\text { cells }\end{array}$ & $\begin{array}{c}\text { Mean } \\
(S D)\end{array}$ & Longest \\
\hline 5-mm rostral & P1 & $15.3(2.5)$ & $11.9(2.1)$ & 14.5 \\
injection & P2 & $663(100)$ & $10.1(1.0)$ & 11.6 \\
& P3 & $11,546(940)$ & - & - \\
& P4 & $10,395(1,023)$ & - & - \\
& Brain & $7,116(1,994)$ & - & - \\
\hline
\end{tabular}

${ }^{\mathrm{a}}$ From cell body to center of injection site. FB, Fast Blue. 

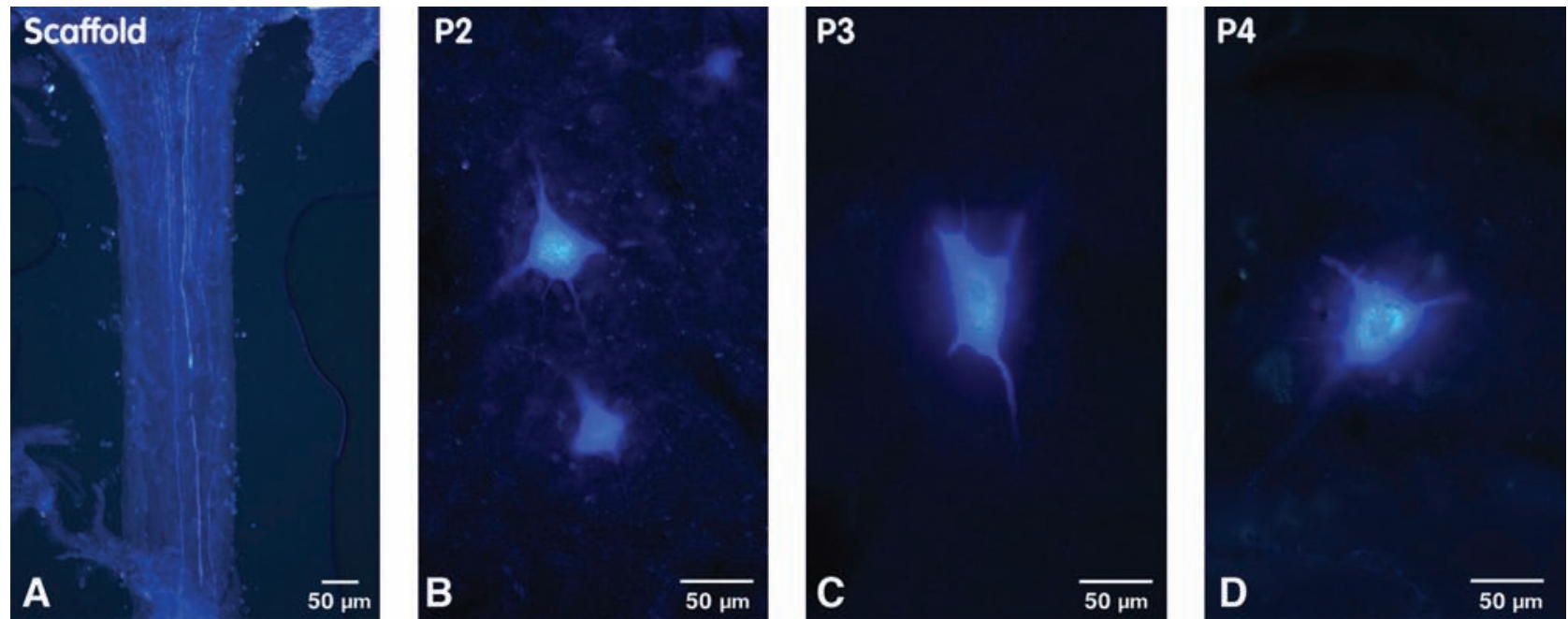

FIG. 5. Confocal microscopic images of FB-labeled regenerated axons and neurons. (A) Longitudinal sections of transected and implanted rat spinal cord showed FB-labeled axons growing through a channel within the scaffold. (B-D) The regenerated neuron cell bodies were labeled in the P2, P3, and P4 segments of the spinal cord rostral to the transection and scaffold. Large neurons (30-50 $\mu \mathrm{m}$ in diameter) were predominantly labeled in the ventral horn. (Color image is available online at www.liebertpub.com/jon)

distribution of dye label at different times after injection and with different volumes of injection. This information is important when interpreting the results of dye tracing as a marker of regeneration in spinal cord injury. A critical question is the distance traveled by axons that have regenerated through an environment that is permissive for axonal growth and then entered a nonpermissive environment.

The observed relationship between time and volume of dye injection decreases the concern that dye might have diffused long distances before being taken up by axons. The label within the halo appeared to be in all cells, confirming that the dye is taken up by cells if it is present in the extracellular space. With these findings, and previous observations that
7 days is required to allow retrograde transport to the most distant cell bodies, we concluded that injection of $0.6 \mu \mathrm{L}$ and tissue harvest after 7 days would provide reliable data and allow us to account for volume of diffusion in the interpretation of our findings.

Under positive control conditions (nontransected animals), neurons were labeled around the injection site (P1), in the cord (P2-P4), and in the pons, midbrain, deep subcortical nuclei, and frontal cortex (Fig. 4). Under negative control conditions (insertion of scaffold containing BMP but no cells), no labeling was seen rostral to the scaffold. This showed that BMP did not support regeneration and that dye did not leak out of the cord and falsely label rostral cells. The uniform number of cells
A

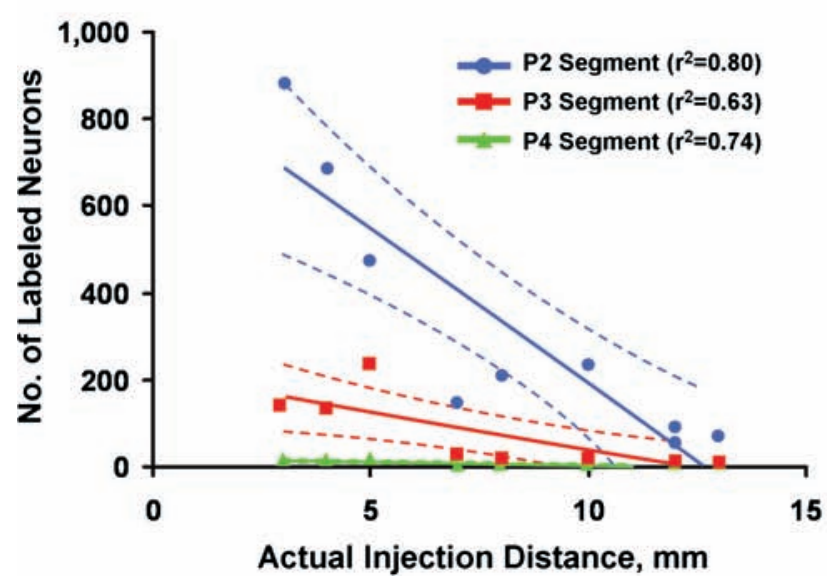

B

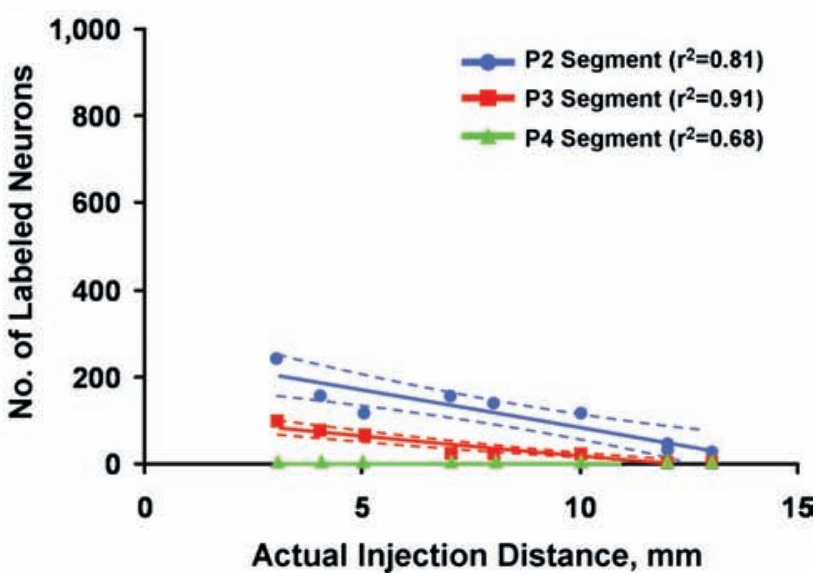

FIG. 6. Linear regression curves. Correlation of the number of FB-labeled regenerated neurons in each segment with the actual injection distance. Each point represents one animal, and each animal generated three data points for each injection site (i.e., the number of cells in P2, P3, and P4). Dashed lines represent 95\% confidence intervals. (A) Graph of labeled neurons in the 1-month injection groups shows significant linear correlation in the P2 $(p=0.001), \mathrm{P} 3(p=0.01)$, and P4 $(p=0.003)$ segments. (B) Similar graph for the 2-month injection group. The linear correlation is maintained for the slopes that are flattened compared with the 1-month injection groups: $\mathrm{P} 2, p=0.001 ; \mathrm{P} 3, p<0.001$; and $\mathrm{P} 4, p=0.006$. (Color image is available online at www.liebertpub.com/jon) 

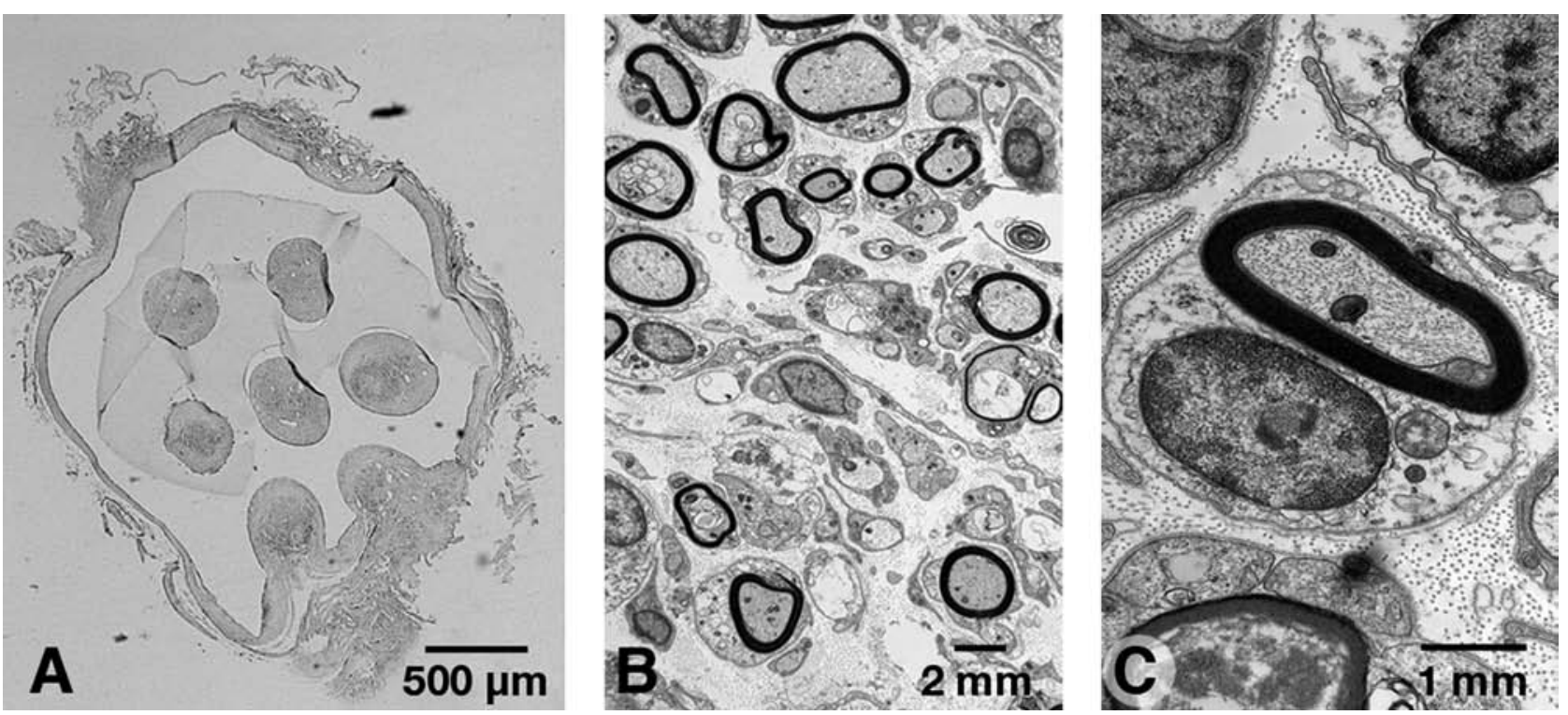

FIG. 7. Light and electron microscopic images of myelinated regenerated axons. (A) Light microscopy of transverse sections of transected and implanted rat spinal cord showed regenerated axons in the channels of the scaffold. The seven channels were slightly distorted but could still be observed after 2 months. (B and C) Transmission electron microscopy showed myelinated axons with typical SC morphology, including extracellular deposition of collagen and basal lamina.

labeled in P1 ( 6,000 cells) indicated uniform injection in all of the groups.

Longitudinal sections showed FB labeling of axons growing throughout the scaffold in transected spinal cords, but labeled axons were seen only within segments close to the injection site (P1, P2, or within the scaffold). In these adjacent areas, punctate extracellular labeling was seen in close proximity to the cell bodies (Fig. 4A and B vs. C and D). This was never observed in more distant segments (P3, P4, and brain), probably because label was concentrated enough in cells to visualize axon terminals on dendritic spines. Cells visualized in controls had the typical morphology of the motor system: long projecting neurons in the rostral cord (P3, P4), pons, deep subcortical nuclei, basal ganglia, and frontal cortex (Fig. $4 \mathrm{C}-\mathrm{H})$. In future studies, it will be interesting to more specifically identify labeled neurons above the craniocervical junction using more detailed anatomical and immunohistochemical techniques. In this study, no neurons were labeled above this level in the transected animals.

After spinal cord transection and scaffold implantation, neurons were labeled in the rostral cord. When dye was injected close to the caudal interface of the scaffold and cord (0-mm group, Tables 3 and 4), 736 neurons $(\mathrm{P} 2+\mathrm{P} 3+\mathrm{P} 4)$ were labeled after 1 month compared with 46,418 labeled neurons $(\mathrm{P} 2+\mathrm{P} 3+\mathrm{P} 4)$ in positive controls (Table 2$)$. This indicates that $1.6 \%$ of neurons projected axons into and through the scaffold. The axons may originate from several different types of neurons. They might be coming from motor system interneurons that projected axons to the caudal cord before transection. This would represent true regeneration. They might originate as collaterals from neurons that were close to the transection site but did not previously project to the caudal cord. Finally, the axons might originate from ventral horn cells that previously projected into roots. After injury, and under the influence of SC in the scaffold, they projected into the scaffold. Each of the latter possibilities, although aberrant, might result in return of function below the lesion. Although the findings demonstrate that a small number of axons grew through the scaffold into the distal cord, we do not have evidence that they reached an appropriate target and established functional connections.

The close linear relationship between number of axons labeled and actual injection distance at 1 and 2 months (Fig. 6A and B) suggests a stochastic process in which a few axons are able to penetrate into the distal cord. The flattening of the linear relationship between number of axons labeled and actual injection distance and the fewer labeled neurons after 2 months suggest that regeneration in this model occurs mostly within a narrow time window after transection injury or that axons regenerating into the distal cord may not have made successful connections and may have retracted or degenerated. This would be similar to the phenomenon of "pruning" in the regenerating peripheral nerve (Brushart et al., 1998).

When dye was injected rostral to the scaffold, the numbers of labeled neurons in P3 and P4 (Table 5) were very close to those in control P3 and P4 segments after 1 month (Table 2), which confirms the consistency of injection. The number of trans-scaffold-labeled neurons 1 month after rostral injection $(\mathrm{P} 2+\mathrm{P} 1$, Table 5) was close to the number of neurons labeled in the reverse direction $(\mathrm{P} 2+\mathrm{P} 3+\mathrm{P} 4$, Table 3$)$ at the same time point.

The use of cell-loaded, biodegradable polymer scaffolds is one approach to bridging the gap after injury of the spinal cord (Xu et al., 1999; Oudega et al., 2001; Friedman et al., 2002; Teng et al., 2002). Microengineered polymer structures potentially can provide guidance, organized cell architecture, and soluble growth or guidance factors impregnated into the polymer matrix. Biologically active molecules may be covalently attached to polymer surfaces, and computer-guided 
stereolithography can construct intricate architecture (Friedman et al., 2002). We used PLGA because it is approved by the U.S. Food and Drug Administration, is readily molded into a simple 7-channel scaffold, and supports regeneration in the nervous system (de Ruiter et al., 2007). Novel polymers derived from synthetic and biological sources are emerging rapidly (Friedman et al., 2002). This is the first detailed study of the use of PLGA in a spinal cord scaffold. Our results confirm that the material is compatible with regeneration and differentiation in the spinal cord.

SCs express axonal growth supporting cell adhesion molecules on their surface (Daniloff et al., 1986; Bixby et al., 1988; Kleitman et al., 1988; Martini and Schachner, 1988) and produce axonal growth-promoting substrates such as laminin (Cornbrooks et al., 1983; Bozyczko and Horwitz, 1986; Ard et al., 1987) and fibronectin (Cornbrooks et al., 1983; Bozyczko and Horwitz, 1986). Almost three decades ago, SCs were shown to support CNS regeneration (Richardson et al., 1980). This observation has been confirmed by many others (BaronVan Evercooren, 1994; Raisman, 1997; Bunge and Pearse, 2003; Oudega et al., 2005; Oudega and $\mathrm{Xu}, 2006)$. In the present study, SCs were introduced in the scaffold, but we cannot exclude the possibility that endogenous SCs from proximal spinal roots migrated into the injured spinal cord (Bresnahan, 1978; Bunge et al., 1994; Takami et al., 2002a).

Although SCs can support CNS regeneration, they may not be practical for use with a clinical approach. A major disadvantage is that they create peripheral nerve architecture within the CNS. Electron microscopy showed that individual SCs ensheathed axons and generated typical peripheral nerve myelin surrounded by a basal lamina (Fig. 7) (Windebank et al., 1985). In the more compact CNS architecture, 1 oligodendrocyte provides myelin for multiple axons and there is no basal lamina. In addition, SCs generated an extensive extracellular collagen matrix (Fig. 7). The basal lamina and extracellular collagen matrix provide flexible mechanical strength that protect the peripheral nervous system (Podratz et al., 2001). For the spinal cord, which has very limited mechanical strength, the spinal column bone provides protection and allows much closer packing of neural cell elements. We estimate that if the spinal cord had the architecture of the sciatic nerve it would have a diameter of $8.8 \mathrm{~mm}$. This reiterates the importance of finding other cells such as stem cells or olfactory ensheathing glia to support regeneration in the spinal cord.

The construct studied here promoted limited regeneration. We showed that long-distance regeneration can occur from CNS neurons that project through a scaffold construct into distal tissue. We have no evidence of functional reconnection, and the number of successfully regenerating axons was small. However, this study serves as an initial step toward reliably quantifying the effects of architecture, cell type, and growth factors on regeneration, from which future studies can be built.

\section{Acknowledgment}

We thank James Tarara for his critical help in imaging of the Fast Blue signals, and LouAnn Gross and Jarred Nesbitt for their excellent technical assistance.

This work was supported by a grant from the NIH (EB002390) and the Wilson, Morton and Mayo Foundations (A.J.W.).

\section{Author Disclosure Statement}

No conflicting financial interest exists.

\section{References}

Akintunde, A., and Buxton, D.F. (1992). Origins and collateralization of corticospinal, corticopontine, corticorubral and corticostriatal tracts: a multiple retrograde fluorescent tracing study. Brain Res. 586, 208-218.

Ard, M.D., Bunge, R.P., and Bunge, M.B. (1987). Comparison of the Schwann cell surface and Schwann cell extracellular matrix as promoters of neurite growth. J. Neurocytol. 16, 539-555.

Asada, Y., Kawaguchi S, Hayashi H, and Nakamura T. (1998). Neural repair of the injured spinal cord by grafting: comparison between peripheral nerve segments and embryonic homologous structures as a conduit of CNS axons. Neurosci. Res. 31, 241-249.

Bamber, N.I., Li, H., Aebischer, P., and Xu, X.M. (1999). Fetal spinal cord tissue in mini-guidance channels promotes longitudinal axonal growth after grafting into hemisected adult rat spinal cords. Neural Plast. 6, 103-121.

Bamber, N.I., Li, H., Lu, X., Oudega, M., Aebischer, P., and Xu, X.M. (2001). Neurotrophins BDNF and NT-3 promote axonal re-entry into the distal host spinal cord through Schwann cellseeded mini-channels. Eur. J. Neurosci. 13, 257-268.

Baron-Van Evercooren, A. (1994). Future prospects in transplantation. Ann. Neurol. 36 Suppl, S151-156.

Bentivoglio, M., Kuypers, H.G., Catsman-Berrevoets, C.E., Loewe, H., and Dann, O. (1980). Two new fluorescent retrograde neuronal tracers which are transported over long distances. Neurosci. Lett. 18, 25-30.

Berry, M., Rees, L., Hall, S., Yiu, P., and Sievers, J. (1988). Optic axons regenerate into sciatic nerve isografts only in the presence of Schwann cells. Brain Res. Bull. 20, 223-231.

Bixby, J.L., Lilien, J., and Reichardt, L.F. (1988). Identification of the major proteins that promote neuronal process outgrowth on Schwann cells in vitro. J. Cell Biol. 107, 353-361.

Bodley, R. (2002). Imaging in chronic spinal cord injury: indications and benefits. Eur. J. Radiol. 42, 135-153.

Bozyczko, D., and Horwitz, A.F. (1986). The participation of a putative cell surface receptor for laminin and fibronectin in peripheral neurite extension. J. Neurosci. 6, 1241-1251.

Bray, G.M., Villegas-Perez, M.P., Vidal-Sanz, M., and Aguayo, A.J. (1987). The use of peripheral nerve grafts to enhance neuronal survival, promote growth and permit terminal reconnections in the central nervous system of adult rats. J. Exp. Biol. 132, 5-19.

Bresnahan, J.C. (1978). An electron-microscopic analysis of axonal alterations following blunt contusion of the spinal cord of the rhesus monkey (Macaca mulatta). J. Neurol. Sci. 37, 5982.

Brockes, J.P., Fields, K.L., and Raff, M.C. (1979). Studies on cultured rat Schwann cells. I. Establishment of purified populations from cultures of peripheral nerve. Brain Res. 165, 105118.

Brushart, T.M., Gerber, J., Kessens, P., Chen, Y.G., and Royall, R.M. (1998). Contributions of pathway and neuron to preferential motor reinnervation. J. Neurosci. 18, 8674-8681.

Bukowska, D., Mierzejewska-Krzyzowska, B., and Zguczynski, L. (2005). Axonal ramification of neurons in the nucleus reticularis tegmenti pontis projecting to the paramedian lobule in the rabbit cerebellum. Neurosci. Res. 51, 15-24.

Bunge, M.B., Holets, V.R., Bates, M.L., Clarke, T.S., and Watson, B.D. (1994). Characterization of photochemically induced 
spinal cord injury in the rat by light and electron microscopy. Exp. Neurol. 127, 76-93.

Bunge, M.B., and Pearse, D.D. (2003). Transplantation strategies to promote repair of the injured spinal cord. J. Rehabil. Res. Dev. 40, 55-62.

Campbell, G., Lieberman, A.R., Anderson, P.N., and Turmaine, M. (1992). Regeneration of adult rat CNS axons into peripheral nerve autografts: ultrastructural studies of the early stages of axonal sprouting and regenerative axonal growth. J. Neurocytol. 21, 755-787.

Casatti, C.A., Frigo, L., and Bauer, J.A. (1999). Origin of sensory and autonomic innervation of the rat temporomandibular joint: a retrograde axonal tracing study with the fluorescent dye fast blue. J. Dent. Res. 78, 776-783.

Chen, A., Xu, X.M., Kleitman, N., and Bunge, M.B. (1996). Methylprednisolone administration improves axonal regeneration into Schwann cell grafts in transected adult rat thoracic spinal cord. Exp. Neurol. 138, 261-276.

Cornbrooks, C.J., Carey, D.J., McDonald, J.A., Timpl, R., and Bunge, R.P. (1983). In vivo and in vitro observations on laminin production by Schwann cells. Proc. Natl. Acad. Sci. USA 80, 3850-2854.

Daniloff, J.K., Levi, G., Grumet, M., Rieger, F., and Edelman, G.M. (1986). Altered expression of neuronal cell adhesion molecules induced by nerve injury and repair. J. Cell Biol. 103, 929-945.

David, S., and Aguayo, A.J. (1981). Axonal elongation into peripheral nervous system "bridges" after central nervous system injury in adult rats. Science 214, 931-933.

de Ruiter, G.C., Onyeneho, I.A., Liang, E.T., Moore, M.J., Knight, A.M., Malessy, M.J., Spinner, R.J., Lu, L., Currier, B.L., Yaszemski, M.J., and Windebank, A.J. (2007). Methods for in vitro characterization of multichannel nerve tubes. J. Biomed. Mater. Res. A 84A, 643-651.

Edoff, K., Grenegard, M., and Hildebrand, C. (2000). Retrograde tracing and neuropeptide immunohistochemistry of sensory neurones projecting to the cartilaginous distal femoral epiphysis of young rats. Cell Tissue Res. 299, 193-200.

Friedman, J.A., Windebank, A.J., Moore, M.J., Spinner, R.J., Currier, B.L., and Yaszemski, M.J. (2002). Biodegradable polymer grafts for surgical repair of the injured spinal cord. Neurosurgery 51, 742-751.

Guenard, V., Kleitman, N., Morrissey, T.K., Bunge, R.P., and Aebischer, P. (1992). Syngeneic Schwann cells derived from adult nerves seeded in semipermeable guidance channels enhance peripheral nerve regeneration. J. Neurosci. 12, 3310 3320.

Guenard, V., Morrissey, T.K., Kleitman, N., Bunge, R.P., and Aebischer, P. (1991). Cultured syngeneic adult Schwann cells seeded in synthetic guidance channels enhance sciatic and optic nerve regeneration [abstract]. Soc. Neurosci. Abstr. 17, 565.

Guenard, V., Xu, X.M., and Bunge, M.B. (1993). The use of Schwann cell transplantation to foster central nervous system repair. Semin. Neurosci. 14, 401-411.

Houle, J.D. (1991). Demonstration of the potential for chronically injured neurons to regenerate axons into intraspinal peripheral nerve grafts. Exp. Neurol. 113, 1-9.

Iwata, A., Browne, K.D., Pfister, B.J., Gruner, J.A., and Smith, D.H. (2006). Long-term survival and outgrowth of mechanically engineered nervous tissue constructs implanted into spinal cord lesions. Tissue Eng. 12, 101-10.

Kleitman, N., Simon, D.K., Schachner, M., and Bunge, R.P. (1988). Growth of embryonic retinal neurites elicited by con- tact with Schwann cell surfaces is blocked by antibodies to L1. Exp. Neurol. 102, 298-306.

Kraus, K.S., and Illing, R.B. (2005). Cell death or survival: molecular and connectional conditions for olivocochlear neurons after axotomy. Neuroscience 134, 467-481.

Kummer, W., and Oberst, P. (1993). Neuronal projections to the guinea pig stellate ganglion investigated by retrograde tracing. J. Auton. Nerv. Syst. 42, 71-80.

LONI Image Viewer. Rat atlas viewer. Los Angeles, CA. Laboratory of Neuro Imaging, UCLA School of Medicine, 2008. Available from: http://www.loni.ucla.edu/Research/Atlases/ Data/rat/RatAtlasViewer.shtml. Accessed December 21, 2008.

Martin, G.F., Terman, J.R., and Wang, X.M. (2000). Regeneration of descending spinal axons after transection of the thoracic spinal cord during early development in the North American opossum, Didelphis virginiana. Brain Res. Bull. 53, 677-687.

Martini, R., and Schachner, M. (1988). Immunoelectron microscopic localization of neural cell adhesion molecules (L1, NCAM, and myelin-associated glycoprotein) in regenerating adult mouse sciatic nerve. J. Cell Biol. 106, 1735-1746.

Moore, M.J., Friedman, J.A., Lewellyn, E.B., Mantila, S.M., Krych, A.J., Ammenuddin, S., Knight, A.M., Lu, L., Currier, B.L., Spinner, R.J., Marsh, R.W., Windebank, A.J., and Yaszemski, M.J. (2006). Multiple-channel scaffolds to promote spinal cord axon regeneration. Biomaterials 27, 419-429.

Oudega, M., Gautier, S.E., Chapon, P., Fragoso, M., Bates, M.L., Parel, J.M., and Bunge, M.B. (2001). Axonal regeneration into Schwann cell grafts within resorbable poly(alphahydroxyacid) guidance channels in the adult rat spinal cord. Biomaterials 22, 1125-1136.

Oudega, M., Moon, L.D., and de Almeida Leme, R.J. (2005). Schwann cells for spinal cord repair. Braz. J. Med. Biol. Res. 38, 825-835.

Oudega, M., and Xu, X.M. (2006). Schwann cell transplantation for repair of the adult spinal cord. J. Neurotrauma 23, 453-467.

Podratz, J.L., Rodriguez, E., and Windebank, A.J. (2001). Role of the extracellular matrix in myelination of peripheral nerve. Glia 35, 35-40.

Porter, S., Clark, M.B., Glaser, L., and Bunge, R.P. (1986). Schwann cells stimulated to proliferate in the absence of neurons retain full functional capability. J. Neurosci. 6, 3070-3078.

Puigdellivol-Sanchez, A., Valero-Cabre, A., Prats-Galino, A., Navarro, X., and Molander, C. (2002). On the use of fast blue, fluoro-gold and diamidino yellow for retrograde tracing after peripheral nerve injury: uptake, fading, dye interactions, and toxicity. J. Neurosci. Methods 115, 115-127.

Quencer, R.M., and Bunge, R.P. (1996). The injured spinal cord: imaging, histopathologic clinical correlates, and basic science approaches to enhancing neural function after spinal cord injury. Spine 21, 2064-2066.

Raisman, G. (1997). Use of Schwann cells to induce repair of adult CNS tracts. Rev. Neurol. (Paris) 153, 521-525.

Richardson, P.M., McGuinness, U.M., and Aguayo, A.J. (1980). Axons from CNS neurons regenerate into PNS grafts. Nature 284, 264-265.

Russo, A., and Conte, B. (1996). Afferent and efferent branching axons from the rat lumbo-sacral spinal cord project both to the urinary bladder and the urethra as demonstrated by double retrograde neuronal labeling. Neurosci. Lett. 219, 155-158.

Smith, G.V., and Stevenson, J.A. 1988. Peripheral nerve grafts lacking viable Schwann cells fail to support central nervous system axonal regeneration. Exp. Brain. Res. 69, 299-306.

Tadie, M., Liu, S., Robert, R., Guiheneuc, P., Pereon, Y., Perrouin-Verbe, B., and Mathe, J.F. (2002). Partial return of 
motor function in paralyzed legs after surgical bypass of the lesion site by nerve autografts three years after spinal cord injury. J. Neurotrauma 19, 909-916.

Takami, T., Oudega, M., Bates, M.L., Wood, P.M., Kleitman, N., and Bunge, M.B. (2002a). Schwann cell but not olfactory ensheathing glia transplants improve hindlimb locomotor performance in the moderately contused adult rat thoracic spinal cord. J. Neurosci. 22, 6670-6681.

Takami, T., Oudega, M., Bethea, J.R., Wood, P.M., Kleitman, N., and Bunge, M.B. (2002b). Methylprednisolone and interleukin10 reduce gray matter damage in the contused Fischer rat thoracic spinal cord but do not improve functional outcome. J. Neurotrauma 19, 653-666.

Teng, Y.D., Lavik, E.B., Qu, X., Park, K.I., Ourednik, J., Zurakowski, D., Langer, R., and Snyder, E.Y. (2002). Functional recovery following traumatic spinal cord injury mediated by a unique polymer scaffold seeded with neural stem cells. Proc. Natl. Acad. Sci. USA 99, 3024-3029.

Vacanti, J.P., and Langer, R. (1999). Tissue engineering: the design and fabrication of living replacement devices for surgical reconstruction and transplantation. Lancet 354, Suppl 1, SI32-134.

Weinberg, E.L., and Raine, C.S. (1980). Reinnervation of peripheral nerve segments implanted into the rat central nervous system. Brain Res. 198, 1-11.
Windebank, A.J., Wood, P., Bunge, R.P., and Dyck, P.J. (1985). Myelination determines the caliber of dorsal root ganglion neurons in culture. J. Neurosci. 5, 1563-1569.

Xu, X.M., Chen, A., Guenard, V., Kleitman, N., and Bunge, M.B. (1997). Bridging Schwann cell transplants promote axonal regeneration from both the rostral and caudal stumps of transected adult rat spinal cord. J. Neurocytol. 26, 1-16.

Xu, X.M., Guenard, V., Kleitman, N., and Bunge, M.B. (1995). Axonal regeneration into Schwann cell-seeded guidance channels grafted into transected adult rat spinal cord. J. Comp. Neurol. 351, 145-160.

Xu, X.M., Zhang, S.X., Li, H., Aebischer, P., and Bunge, M.B. (1999). Regrowth of axons into the distal spinal cord through a Schwann-cell-seeded mini-channel implanted into hemisected adult rat spinal cord. Eur. J. Neurosci. 11, 1723-1740.

Address correspondence to: Anthony J. Windebank, M.D.

Department of Neurology Mayo Clinic 200 First Street SW Rochester, MN 55905

E-mail: windebank.anthony@mayo.edu 
